\title{
A ADOÇÃO DE ESTRATÉGIAS DE BYOd NO ENSINO SUPERIOR DE ADMINISTRAÇÃO
}

ADOPTION OF BYOD STRATEGIES IN COLLEGE EDUCATION OF ADMINISTRATION

Recebido em 30.04.2014. Aprovado em 07.10.2014 Avaliado pelo sistema double blind review

DOI: http://dx.doi.org/10.12712/rpca.v8i4.437

\author{
Carlos David Cequeira Feitor \\ carlos.feitor@gmail.com \\ Universidade Federal do Rio Grande do Norte - Natal - RN - Brasil
}

\section{Marcos Paulo da Silva}

marcosilva.paulo@gmail.com

Universidade do Estado do Pará - Belém - PA - Brasil

\section{Manoel Veras de Sousa Neto}

manoel.veras@uol.com.br

Universidade Federal do Rio Grande do Norte - Natal - RN - Brasil

\section{Adrianne Paula Vieira de Andrade}

adriannepaula@gmail.com

Universidade Federal do Rio Grande do Norte - Natal - RN - Brasil

\section{Resumo}

Diante da difusão do uso de dispositivos eletrônicos móveis de informação no ambiente de trabalho e acadêmico, este estudo investigou a propensão de estudantes do ensino superior de Administração de uma instituição privada e outra pública, em aderir a um programa de BYOD. Trata-se de um estudo qualitativo, exploratório e descritivo, onde a estatística descritiva foi utilizada para dimensionar aspectos da posse ou não de dispositivos e a participação em um programa de BYOD e a estatística inferencial para identificar diferenças entre as instituições em relação à utilização dos dispositivos, através do teste de Mann-Whitney. Conclui-se que a insegurança, características físicas, funcionalidade e a insuficiência de instalações, influenciam na heterogeneidade das perspectivas em relação ao tipo de instituição.

Palavras-chave: Dispositivos Eletrônicos Móveis. Ensino Superior. Tecnologia da Informação.

\begin{abstract}
Given the widespread use of mobile electronic devices of information in work and academic environment, this study investigated the propensity of students in higher education administration from a private institution and a public one, to adhere to a BYOD program. It is a qualitative, exploratory and descriptive study, where descriptive statistics were used to scale aspects of owning or not owning devices and participation in the BYOD program and inferential statistics to identify differences between institutions in relation the use of devices, using the
\end{abstract}


Mann-Whitney test. We conclude that insecurity, physical features, functionality and inadequate facilities, influence the heterogeneity of perspectives in relation to the type of institution.

Keywords: Mobile Electronic Devices. College Education. Information Technology.

\section{Introdução}

O avanço do emprego da Tecnologia da Informação (TI) nas práticas educacionais foi impulsionado pela disponibilidade de dispositivos móveis que permitiram as Instituições de Ensino Superior (IES) a ampliarem a adoção de estratégias que integram a TI às práticas das disciplinas, podendo influenciar positivamente a qualidade da educação (KOBUS; RIETVELD; OMMEREN, 2013).

Apesar do uso de dispositivos móveis não ser universal, muitos estudantes utilizam tecnologias móveis e outros equipamentos de TI para comunicação e para o acesso a materiais didáticos (JONES et al., 2010). A disseminação da tecnologia móvel proporciona muitas oportunidades para alavancar o desempenho e aprendizagem dos alunos, tanto em sala de aula quanto fora dela (MARTIN; ERTZBERGER, 2013). Os dispositivos móveis possibilitam novas maneiras de estudar e aprender em ambientes diferentes daqueles concedidos pela sala de aula, fornecendo acesso a informação, processamento e comunicação de forma contínua. (LACINA, 2008; MEURANT, 2010; SHEPPARD, 2011).

No entanto, o contínuo surgimento de tecnologias muitas vezes impede o amadurecimento das mesmas e a compreensão da forma como estas influenciam os seus usuários, sendo este entendimento crucial para que as instituições de ensino possam realizar investimentos estratégicos na planta física e técnica de infraestrutura e no desenvolvimento do seu quadro profissional a fim de definir formas mais eficazes de ensino (DEDE, 2005).

Adicionalmente, têm-se alunos com uma compreensão limitada de qual TI podem adotar e como ela pode apoiar a sua própria aprendizagem. Estas descobertas desafiam a proposição de que os jovens possuem conhecimentos tecnológicos sofisticados (MARGARYAN; LITTLEJOHN; VOJT, 2011).

Assim, uma das estratégias de TI adotadas por algumas IES é o incentivo ao aluno a levar seu próprio dispositivo móvel para a instituição - em inglês, Bring Your Own Device (BYOD), o qual seria integrado às práticas educacionais da instituição, podendo, inclusive, reduzir gastos com investimento em infraestrutura de laboratórios que envolvem serviços intensivos em capital e ociosidade pela flutuação da demanda (ATKINSON; SPENNEMAN; CONFORTH, 2005).

Todavia, apesar destes e outros argumentos favoráveis ao uso de dispositivos móveis, de acordo com Kobus, Rietveld e Ommeren (2013), ainda tem-se uma literatura limitada sobre a propriedade de dispositivos móveis de TI pelo corpo discente e sua disposição em levá-los às aulas. Os autores também afirmam que apesar destes dispositivos serem utilizados pelos estudantes de diversas formas, poucas vezes são incorporados às atividades de classe.

Este estudo tem por objetivo avaliar a disposição dos alunos do curso de Administração de uma instituição privada e uma instituição pública em levar seus dispositivos móveis para as respectivas IES, bem como entender o que influencia as suas percepções sobre estratégias de BYOD. Além disso, o estudo visa verificar a existência de convergências e divergências entre o comportamento dos alunos devido à natureza das instituições pública ou privada. Antes, porém, verifica-se a posse destes alunos de dispositivos eletrônicos móveis de TI, neste caso 


\section{Carlos David Cequeira Feitor, Marcos Paulo da Silva, Manoel Veras de Sousa Neto, Adrianne Paula Vieira de Andrade}

smartphone, tablet e/ou notebook.

Ainda, foram levantados os motivos que induziriam o estudante a levar o dispositivo à instituição, assim como, a sua frequência semanal de utilização na instituição e o parecer do mesmo sobre a adoção de uma estratégia de uso do próprio dispositivo nas atividades do curso. Por fim, verificaram-se as diferenças de percepção com relação à instituição dos alunos, e as razões para levarem ou não seus dispositivos eletrônicos móveis de TI à instituição.

\section{Perspectivas sobre a adoção de estratégias de COPE e BYOD}

A sigla COPE (corporate-owned, personally-enabled) representa o modelo de negócio no qual a organização fornece dispositivos móveis aos colaboradores e permite que estes os usem para finalidade pessoal (OLIVEIRA, 2012). Neste caso a propriedade do equipamento móvel é da empresa, bem como os custos mensais pelo uso do dispositivo. Porém, os colaboradores são beneficiados pelo uso pessoal, ou seja, podem desfrutar do equipamento em locais e situações não relacionados a questões profissionais. (SPROSTS, 2013).

O modelo COPE contribui para aperfeiçoar a gestão dos dispositivos móveis da organização (MDM - Mobile Device Management), e favorece as iniciativas de gestão dos aplicativos móveis (MAM - Mobile Application Management), proporcionando a empresa maior proteção técnica e legal dos dados, e pode reduzir os custos e despesas operacionais (ROUSE, 2013). 0 objetivo do modelo é aumentar a segurança global do negócio através do monitoramento e proteção dos equipamentos.

No entanto, em muitas ocasiões os funcionários preferem utilizar seus próprios dispositivos para realização de suas tarefas, uma vez que os mesmos proporcionam alto poder de acesso e processamento de informações, permitindo ao usuário escolher a ferramenta que ofereça maior produtividade (KEMSHALL, 2012). Por isso, no presente artigo o modelo BYOD será considerado como referência balizadora para as discussões e análises do trabalho.

O termo Bring Your Own Device (BYOD) representa a adoção, pelo integrante da organização, de dispositivos ou equipamentos móveis próprios em serviços, políticas e tecnologias nas organizações para a realização das atividades profissionais (DAVIS, 2012), dentre estes dispositivos se destacam: smartphones, tablets e notebooks. Segundo Thomson (2012), o BYOD é uma estratégia que permite e estimula os colaboradores a trazerem os seus dispositivos móveis para uso profissional, proporcionando redução nos investimentos em hardware e a ampliação da produtividade da empresa.

A Cisco elaborou uma pesquisa, em 2012, com os gestores de TI, e revelou que mais de dois terços dos entrevistados descrevem a estratégia BYOD como positiva ou muito positiva para as organizações. Os pesquisadores também identificaram que $76 \%$ dos gerentes de TI consideram a influência de dispositivos como valiosa ou muito valiosa para os negócios. Os principais benefícios da adoção do BYOD citados pelos entrevistados estão relacionados com o aumento da produtividade dos colaboradores, incremento nas oportunidades de colaboração e maior satisfação nas atividades ordinárias do trabalho. Na opinião de $80 \%$ dos gerentes de TI, as empresas com políticas de BYOD têm uma vantagem competitiva sobre as outras organizações.

Diante do cenário apresentado, os gestores procuram elaborar políticas e modelos de gestão que visam incentivar o uso dos dispositivos próprios de maneira segura e produtiva para a organização. No entanto, para viabilizar a adoção dos dispositivos móveis é necessário realizar 
investimentos em infraestrutura e segurança, objetivando preservar a integridade das informações vitais para manutenção do negócio, bem como garantir a efetividade na condução das tarefas empresariais (MORROW, 2012).

Nesse sentido, a implantação de um sistema de gestão dos dispositivos móveis requer dos responsáveis pelo projeto de planejamento e execução considerar uma série de requisitos e riscos que possam interferir no sucesso do projeto. Na visão de Vickermon (2013), ao implantar um projeto com tecnologia móvel, é importante estruturar o projeto em etapas, com o objetivo de mitigar os riscos envolvidos na adoção do modelo proposto.

Deste modo, ao tratar uma nova tecnologia, é imprescindível traçar um estudo específico sobre as possíveis aplicações dos equipamentos na corporação, buscando entender e definir como o dispositivo pode ser integrado de maneira produtiva. Pettey e Meulen (2012) destacam os seguintes aspectos a serem considerados para a implementação de BYOD: a) investigar as demandas específicas das funções empresariais e as suas restrições; b) definir os usuários chave envolvidos no planejamento, implementação e disseminação do modelo proposto; c) determinar o período de testes dos recursos BYOD, para os usuários formarem impressões e avaliar a confiabilidade da solução; d) estabelecer os termos de compromisso, contemplando o nível e tipo de acesso aos dados da empresa, assim como os horários de uso dos equipamentos; e) por fim, instituir os elementos de segurança. Por consequência da apreciação dos aspectos anteriores, os gestores poderão restringir os riscos de implantação, e em contrapartida usufruir dos ganhos de competitividade resultante dos novos patamares de mobilidade, agilidade e produtividade sustentados por uma infraestrutura sólida.

Algumas outras referências mais recentes relacionadas ao BYOD tratam da segurança dos dados e fraudes (TOKUYOSHI, 2013), adoção dos dispositivos móveis nas empresas (FINNERAN, 2011), o impacto no ambiente de trabalho (MESSMER, 2013) e, por fim, a gestão de equipamentos móveis empresariais e suas implicações (RALPH, 2012).

\section{O BYOD nas instituições de ensino}

A propagação da TI despertou a discussão do uso das estratégias BYOD nas escolas, universidades e outras IES. (FORTSON, 2013). Estudos anteriores analisaram o uso dos equipamentos móveis direcionados para a aprendizagem. Após a realização de uma pesquisa nas bases de dados internacionais, foram identificados quatro eixos que norteiam tais estudos, os quais são: os aspectos educacionais, aspectos sociais, aspectos comportamentais e socioeconômicos. A saber:

\begin{tabular}{|l|l|l|}
\hline \multicolumn{1}{|c|}{$\begin{array}{c}\text { EIXOS } \\
\text { TEMÁTICOS }\end{array}$} & \multicolumn{1}{|c|}{$\begin{array}{c}\text { TEMAS } \\
\text { RELACIONADOS }\end{array}$} & \multicolumn{1}{c|}{ AUTORES(AS) } \\
\hline \multirow{4}{*}{$\begin{array}{l}\text { Aspectos } \\
\text { Educacionais }\end{array}$} & Aprendizagem & Ozcelik e Acarturk (2011) \\
\cline { 2 - 3 } & $\begin{array}{l}\text { Aprendizagem e } \\
\text { atitudes }\end{array}$ & $\begin{array}{l}\text { Martin e Ertzberger (2013); Fortson } \\
\text { (2013); Johnson (2012) }\end{array}$ \\
\cline { 2 - 3 } & $\begin{array}{l}\text { Desempenho dos } \\
\text { alunos }\end{array}$ & $\begin{array}{l}\text { Rockinson-Szapkiw et al. (2013); Fried } \\
\text { (2008); Tamim et al. (2011). }\end{array}$ \\
\cline { 2 - 3 } & $\begin{array}{l}\text { Aquisição de } \\
\text { conhecimento }\end{array}$ & Furió et al. (2013). \\
\hline
\end{tabular}




\section{Carlos David Cequeira Feitor, Marcos Paulo da Silva, Manoel Veras de Sousa Neto, Adrianne Paula Vieira de Andrade}

\begin{tabular}{|l|l|l|}
\hline \multirow{4}{*}{$\begin{array}{l}\text { Aspectos } \\
\text { Comportamentais }\end{array}$} & $\begin{array}{l}\text { Comportamento e } \\
\text { adoção }\end{array}$ & $\begin{array}{l}\text { Shin et al. (2011); Finneram (2011); } \\
\text { Molina et al. (2013); Tokuyoshi (2013); } \\
\text { Messmer (2013) }\end{array}$ \\
\cline { 2 - 3 } Aspectos Sociais & Desempenho & $\begin{array}{l}\text { Junco (2012); Sung e Mayer (2013); } \\
\text { Vickermon (2013) }\end{array}$ \\
\cline { 2 - 3 } & $\begin{array}{l}\text { Pemunidade e } \\
\text { universidade } \\
\text { educação }\end{array}$ & Idrus e Ismail (2010). \\
\cline { 2 - 3 } & Adoção & Taleb e Sohrabi (2012). \\
\hline \multirow{4}{*}{$\begin{array}{l}\text { Aspectos } \\
\text { Socioeconômicos }\end{array}$} & Adoção & Marinagi, Skourlas e Belsis (2013). \\
\cline { 2 - 3 } & Adoção e educação & Jones et al. (2010) \\
\cline { 2 - 3 } & $\begin{array}{l}\text { Computação, adoção } \\
\text { e internet }\end{array}$ & $\begin{array}{l}\text { Sautter, Tippett e Morgan, (2010); } \\
\text { Talukdar e Gauri, (2011). }\end{array}$ \\
\cline { 2 - 3 } & adoção & $\begin{array}{l}\text { Vekiri (2010); Padmanabhan e Wise } \\
\text { (2012). }\end{array}$ \\
\cline { 2 - 3 } & Socialização e ensino & Margaryan, Littlejohn e Vojt (2011). \\
\cline { 2 - 3 } & BYOD & Kobus, Rietveld e Ommeren (2013). \\
\hline
\end{tabular}

Quadro 1 - Eixos temáticos sobre a utilização de dispositivos móveis de TI.

Fonte: Resultados da Pesquisa (2013)

Johnson (2012) elenca os principais fatores que incentivam os estudantes a trazerem os equipamentos digitais pessoais para Universidade, a saber: a) os tablets, notebooks, e-books, readers, netbooks e smartphones estão mais acessíveis financeiramente para as famílias; b) as pessoas estão percebendo os benefícios da computação ubíqua nas tarefas diárias; c) os professores estão empregando estratégias de ensino que requerem o uso de tecnologia pessoal, com o propósito de motivar os discentes; d) as instituições de ensino reconhecem a impossibilidade de providenciar dispositivos para todos os alunos, uma vez que os custos seriam proibitivos.

Martin e Ertzberger (2013) investigaram as implicações da aprendizagem móvel no sucesso e atitudes dos estudantes. Participaram da pesquisa 109 alunos de graduação matriculados nos cursos de tecnologia e design instrucional de uma Universidade regional Norte Americana. 87\% dos entrevistados eram mulheres, e $13 \%$ homens. $75 \%$ dos pesquisados possuíam idade entre 18 e 25 anos. Os autores identificaram que o uso de ipad/ipod acarretou em atitudes positivas. Segundo os pesquisadores os dispositivos móveis aumentam o envolvimento dos alunos nas atividades acadêmicas. Os estudantes que usaram o IPAD eram mais comprometidos, animados e motivados pela nova tecnologia em comparação com aqueles que não possuíam o dispositivo móvel. Os autores também destacaram que os estudantes desfrutaram do tipo de aprendizagem que esse tipo de dispositivo proporciona. Portanto, o estudo revelou que as instituições deveriam incentivar a adoção de dispositivos móveis, pois os alunos mostram-se mais comprometidos e envolvidos a aprendizagem. 
Rockinson-Szapkiw, Courduff, Carter et al. (2013) estudaram a relação entre o formato do texto e o desempenho dos alunos que usam equipamentos móveis. Os resultados demostraram que não existe diferença de aprendizagem entre os grupos, sugerindo que os textos eletrônicos e tradicionais são equivalentes em termos de aprendizagem. Participaram da pesquisa 538 estudantes de graduação presencial e cursos online de uma Universidade privada localizada nos Estados Unidos. A principalmente contribuição do artigo reside na constatação de que o uso de textos eletrônicos não melhoram a aprendizagem cognitiva ou as notas dos alunos. Por isso, adotar o uso obrigatório de dispositivos móveis e textos eletrônicos para melhor o desempenho acadêmico pode resultar em uma ação ineficaz.

Já Furió, González-Gancedo, Juan et al. (2013) realizaram um estudo comparativo, no qual concluíram que o peso e o tamanho do dispositivo móvel não influenciam na capacidade de aquisição do conhecimento. Os autores também concluíram que o uso de smartphones e tablets podem contribuir para propósitos de aprendizagem, e os dispositivos podem contribuir como ferramentas de apoio em ambientes de aprendizagem. Outro trabalho relevante alinhado as perspectivas do artigo em questão, Ozcelik e Acarturk (2011) verificaram que os dispositivos móveis por facilitarem o acesso às informações on-line, aumentam o potencial de aprendizagem dos alunos. A pesquisa foi realizada na Universidade de Atilim, localizada na Turquia. 0 experimento contou com 44 estudantes de graduação. Os autores também observaram que os estudantes preferem os livros em comparação aos livros digitais. Todavia, os dispositivos móveis proporcionam a oportunidade de integrar informações digitais e textos impressos. Ainda constataram que os smartphones complementam as fontes de informações impressas de maneira mais efetiva que os notebooks, sugerindo as instituições desenvolver políticas dirigidas a dispositivos móveis de baixo custo, tais como, o smartphone e tablets.

A segunda linha proposta para o embasamento teórico do presente artigo refere-se aos aspectos comportamentais e o uso de dispositivos. Shin, Shin, Choo et al. (2011) observaram que os usuários de smartphone podem usar esse tipo de dispositivo como ferramenta de comunicação, assim como uma aplicação de aprendizagem móvel. Participaram da pesquisa 10 Universidades públicas e privadas da Coréia do Sul, cujas instituições adotam o uso de smartphones como ferramenta de aprendizagem. 0 total de questionários respondidos correspondeu a 298, no entanto, foram aproveitados 215 . Os autores relataram $75,8 \%$ dos estudantes usam o smartphone para fins acadêmicos e de aprendizagem. Por isso, os pesquisadores oferecem um modelo de avaliação do comportamento dos usuários de smartphone e propõe alternativas de adoção do dispositivo móvel nas Universidades. 0 estudo realizado por Junco (2012) estabelece uma relação entre o desempenho acadêmico e as ações multitarefas dos alunos. 0 autor examinou a frequência dos estudantes em realizar ações multitarefas por meios dos dispositivos eletrônicos durante as aulas, e as consequências desses acessos na nota final.

Sung e Mayer (2013) elaboraram uma pesquisa cujo objetivo seria analisar o desempenho dos alunos ao adotar dispositivos móveis, em comparação aos usuários de desktop. Participaram do estudo 89 estudantes da Universidade da Califórnia matriculados no curso de Psicologia. Dos envolvidos na pesquisa, 34 correspondiam ao gênero masculino, enquanto 55 ao feminino. Os autores relataram que o grupo de estudantes que adotaram o dispositivo móvel, como instrumento de aprendizagem, pode aumentar a disposição dos mesmos em continuar engajados nos estudos. Todavia, o uso dos equipamentos móveis não melhora o desempenho. Neste caso, politicas institucionais orientadas para o uso de dispositivos móveis podem contribuir no aumento da motivação e engajamento dos alunos.

Outros estudos mostram-se relevantes para entender a efetividade dos equipamentos portáteis 


\section{Carlos David Cequeira Feitor, Marcos Paulo da Silva, Manoel Veras de Sousa Neto, Adrianne Paula Vieira de Andrade}

na aprendizagem. Destaca-se, neste caso, o trabalho de Molina, Redondo, Lacave et al. (2013) que concluiu que os dispositivos móveis com limitação de visualização (como o smartphones) não são adequados para acessar e visualizar materiais de ensino, em função da sobrecarga cognitiva imposta pelos dispositivos. Segundo os pesquisados, o ipad seria o dispositivo adequado e que proporciona maior motivação. 0 estudo foi realizado no College of Computer Science (SCI), localizada na Ciudad Real. Participaram da pesquisa 20 estudantes e 5 professores. Os autores sugerem futuros trabalhos que considerem características individuais e comportamentais, tais como diferenças culturais e aspectos socioeconômicos, visando medir os efeitos dessas características na aprendizagem por meio de dispositivos móveis.

Na linha deste trabalho, Idrus e Ismail (2010) investigaram o papel das instituições de ensino superior na concepção de uma comunidade do conhecimento, através do uso dos dispositivos moveis. Os pesquisadores revelaram que as tecnologias de aprendizagem móvel auxiliam a transmissão e entrega de conteúdo multimídia. Por isso, as instituições são responsáveis pela construção de um ambiente que favoreça o ensino e o processo de aprendizagem, assim como a elaboração de conteúdo adequado para o uso em dispositivos móveis. Os autores apresentam um conjunto de casos em diferentes Universidades (Pretoria, Manchester e Sains Malasia), visando ilustrar as práticas empregadas por estas instituições de ensino ao adotar ambientes móveis de aprendizagem.

Outro importante estudo foi realizado por Taleb e Sohrabi (2012), cujo objetivo foi investigar a percepção dos alunos quanto ao uso educacional dos dispositivos móveis. Para este trabalho, os pesquisadores consideram aspectos como o gênero para verificar a existência de efeitos significantes no uso de dispositivos móveis. Foram selecionados 289 estudantes dos cursos de Psicologia e Educação da Universidade Islâmica Azad em Israel. Segundo os pesquisadores o gênero possui efeito significante no uso educacional do dispositivo móvel. Constataram também que possuir um equipamento com diversas funcionalidades, afeta significativamente as atividades que os alunos desempenharam na Universidade. Por fim, destaca-se, que o tipo de curso, a idade e renda não apresentam correlação significante na quantidade de uso do dispositivo móvel.

Marinagi, Skourlas e Belsis (2013) elaboraram um estudo a respeito da adoção dos dispositivos da computação ubíqua na educação superior, visando investigar como estes equipamentos podem ser empregados nas instituições de ensino, bem como o seu impacto na aprendizagem dos alunos, considerando diferentes aspectos socioeconômicos. A pesquisa foi realizada no Departamento de Informática do Instituto Educacional de Tecnologia em Atenas. Participaram do estudo 14 estudantes, 5 instrutores e 1 especialista em Educação. Foram realizadas entrevistas semiestruturadas para capturar as experiências dos entrevistados no uso dos dispositivos móveis, assim como as impressões quanto aos ambientes virtuais de aprendizagem. Os autores observaram que os ambientes de aprendizagem na modalidade ubíqua equipadas com os dispositivos e tecnologias móveis adequados podem envolver mais os estudantes com o processo de aprendizagem, aumentando a efetividade do sistema educacional.

Por fim, o quarto eixo temático constituinte dos elementos teóricos do corrente trabalho, referese à tecnologia da informação e aspectos socioeconômicos. Este eixo possui forte aderência ao estudo em questão, uma vez que procura entender em que medida os indicadores socioeconômicos, tais como, renda, gênero, etnia e nível de educação influenciam na adoção e uso de computadores (VEKIRI, 2010; PADMANABHAN; WISE, 2012), internet (SAUTTER; TIPPETT; MORGAN, 2010; TALUKDAR; GAURI, 2011) e celulares (FONG, 2009). Vale ressaltar 
outros três trabalhos que dissertam sobre a propriedade dos dispositivos móveis e como estes equipamentos são usados para a aprendizagem.

Margaryan, Littlejohn e Vojt (2011) examinaram a propriedade dos dispositivos móveis pelos estudantes e a maneira que a tecnologia digital era empregada no ensino e socialização. Para tanto, inicialmente foi elaborado um questionário para levantar o tipo de tecnologia que os estudantes adotam e com que frequência usam para finalidades de aprendizagem e socialização. Em seguida, conduziram entrevistas com os alunos para entender como usavam a tecnologia. Os pesquisadores verificaram que $66,3 \%$ possuem um notebook e $99,4 \%$ um celular. Os autores concluíram que os estudantes favorecem formas de aprendizagem e ensino de maneira convencional, passiva e linear. E que as expectativas da integração das tecnologias digitais com o ensino deveriam concentrar nas ferramentas pedagógicas tradicionais.

Jones et al. (2010) discutem os fatores que influenciam a adoção de tecnologias móveis, concentrando nas variáveis de idade e tipo de educação. Os pesquisadores realizaram o estudo em 5 Universidades provenientes da Inglaterra, e consideraram 14 tipos de cursos diferentes. 0 instrumento de coleta permitiu levantar aspectos referentes ao uso da tecnologia móvel para fim pessoal e acadêmico, considerando quatro sessões principais: características demográficas, acesso a tecnologia, o uso da tecnologia na Universidade e uso da tecnologia para atividades específicas do curso. $77,4 \%$ dos pesquisados possui um notebook, enquanto que 75,7\% usufruem de um celular com acesso a internet. Os mesmos autores recomendam futuros estudos que contemplem o efeito das variáveis socioeconômicas sobre o uso das tecnologias móveis digitais.

No trabalho de Kobus, Rietveld e Ommeren (2013) os autores estudaram em que medida os alunos são afetados pelas estratégias BYOD das universidades. Para isso, os pesquisadores perscrutaram em que nível a renda, idade, tipo de educação e outras variáveis afetam a propriedade dos dispositivos móveis digitais. Participaram da pesquisa 3132 estudantes da Universidade Dutch, instituição sediada na Holanda. Os pesquisados responderam a um questionário sobre a propriedade e uso de notebooks, tablets e smartphones. Os autores constataram que $96 \%$ dos estudantes possuem pelo menos um tipo de dispositivo móvel. Verificaram também, através da modelagem econométrica, que a renda da família, a renda do aluno, o gênero e o tipo de residência possui significância estatística, porém um efeito pequeno na propriedade dos equipamentos móveis. Constataram que as taxas de propriedade dos dispositivos são altas para todos os grupos de alunos, incluindo os de baixa renda. Entretanto, os alunos deixam seus notebooks em casa na maioria do tempo, uma vez que acham incomodo carregar o equipamento. Por fim, foi observado que os alunos acham uma má ideia abolir os laboratórios de informática da universidade e substitui-los por dispositivos próprios.

\section{Metodologia}

Esta pesquisa é caracterizada como qualitativa, exploratória e descritiva visto que se propõe a estudar as características dos alunos de Administração de duas IES, sendo uma pública e a outra privada, a fim de levantar opiniões e atitudes relevantes em relação a variáveis relacionadas à participação em um programa de BYOD. Além disso, o estudo propõe a realização de associações entre estas variáveis.

Em junho de 2013, 289 estudantes do curso de Administração da instituição pública responderam um questionário sobre a posse de dispositivos móveis de TI e outras variáveis explicativas, tais como, idade, gênero, turno, renda do aluno e renda familiar, sendo a primeira variável contínua e as demais categóricas, a fim de avaliar elementos que influenciariam na 


\section{Carlos David Cequeira Feitor, Marcos Paulo da Silva, Manoel Veras de Sousa Neto, Adrianne Paula Vieira de Andrade}

adoção de uma estratégia de BYOD pela instituição. Em novembro de 2013, o mesmo questionário foi aplicado ao mesmo número de discentes do curso de Administração de uma instituição privada, objetivando avaliar as mesmas variáveis, bem como estabelecer comparações entre as duas amostras, perfazendo um total de 578 respondentes.

Utilizou-se a estatística descritiva para dimensionar informações referentes a aspectos que envolvem a posse ou não de dispositivos pelos discentes, dentre eles: a situação e localização da moradia; a frequência com que os dispositivos são trazidos a instituição; um parecer sobre a obrigatoriedade do próprio notebook nas atividades do curso e as razões que influenciam o discente a trazer ou não o dispositivo à instituição.

A última etapa de análise dos dados consistiu na utilização da estatística inferencial para identificar se haviam diferenças estatísticas significantes quanto ao gênero e a instituição dos respondentes com relação às razões para eles não levarem o notebook a instituição e os motivos que os fazem trazerem seus dispositivos à instituição.

Primeiramente, foi testada a normalidade das variáveis para identificar a estatística que seria utilizada. Foi aplicado o teste de Kolmogorov-Smirnov o qual demonstrou que as variáveis utilizadas nesta pesquisa não estão em uma distribuição normal. Como não se observou o pressuposto da normalidade, foi utilizado o teste de significância não-paramétrico de MannWhitney (Teste U) para amostras independentes. Segundo Dancey e Reidy (2006 ,p. 528), o teste de Mann-Whitney avalia se existe uma diferença estatística significativa entre as médias dos postos das condições da pesquisa.

Os testes estatísticos não paramétricos podem ser utilizados quando a amostra tem uma distribuição que não é normal. Nesta pesquisa, foram utilizados alguns testes com dois subgrupos em cada um deles. Inicialmente, para avaliar se homens e mulheres diferem de opinião com relação às razões para levar e não levar os seus dispositivos à instituição. E, em seguida, para identificar diferenças entre indivíduos de instituição pública e privada com relação a tais variáveis. A hipótese nula destes testes é que as médias da população são as mesmas para os dois grupos. A comparação entre os grupos foi feita tomando como base as posições (ranks) dos elementos da amostra. Para isto, foi utilizado um nível de significância $\alpha$ de 0,05 .

\section{Resultados}

\section{Análises descritivas}

Com base nas estatísticas descritivas os resultados demonstram que os respondentes da instituição pública são $57 \%$ do gênero masculino e 54\% do turno matutino. Quanto à renda, o maior grupo de alunos (45\%) possui uma renda inferior a $\mathrm{R} \$ 678,00$, no entanto a renda familiar entre $\mathrm{R} \$ 3.390$ - $\mathrm{R} \$ 10.170,00$ representa o maior grupo com $37 \%$ dos estudantes. $\mathrm{Na}$ instituição privada, verifica-se que $54 \%$ são do gênero feminino e $73 \%$ do turno da noite. Esta instituição não possui alunos matriculados no turno matutino. Quanto à renda, $57 \%$ do grupo de alunos estão na faixa entre $R \$ 678,00$ - $R$ \$ 2.034,00, e 34\% na faixa de renda inferior a $R \$$ 678,00 .

A idade média dos discentes da instituição pública é de 22,37 anos e, em relação à posse de dispositivos móveis, $20 \%$ deles possuem tablet, $74 \%$ smartphone e $81 \%$ possui notebook. A idade média dos alunos da instituição privada corresponde a 25,44 anos, destes $17 \%$ possuem 
tablet, 64\% smartphone e 79\% possui notebook. Este fato corrobora os estudos de Margaryan, Littlejohn e Vojt (2011) e Johnson (2012), demonstrando a ampliação do acesso a estes dispositivos, que neste caso pode ser percebido tanto na instituição privada quanto na pública.

Mediante os dados apresentados na tabela 1, observa-se que em ambas as instituições a posse do notebook e tablet são equivalentes. Contudo, ao estabelecer uma comparação entre os valores percentuais do smartphone entre as instituições, constata-se que os alunos do curso de Administração da instituição pública possuem 10\% a mais do referido dispositivo, esta diferença pode estar associada ao menor nível de comprometimento da sua renda, por se tratar de uma IES pública, e vale ressaltar que conforme Ozcelik e Acarturk (2011) os smartphones seriam mais efetivos na complementação dos estudos das informações impressas, o que daria uma margem de vantagem as IES públicas em terem êxito, caso adotassem estratégias de BYOD nas suas práticas de ensino.

\begin{tabular}{llcccc} 
& & \multicolumn{3}{c}{ Instit. Pública } & \multicolumn{2}{c}{ Instit. Privada } \\
\hline DISPOSITIV0 & Tipo de Posse & Frequência & (\%) & Frequência & $(\%)$ \\
\hline \multirow{2}{*}{ Notebook } & Não possui & 56 & $19 \%$ & 58 & $20 \%$ \\
& $\begin{array}{l}\text { Posse } \\
\text { compartilhada }\end{array}$ & 35 & $12 \%$ & 46 & $16 \%$ \\
& Posse exclusiva & 198 & $69 \%$ & 179 & $63 \%$ \\
\hline \multirow{2}{*}{ Tablet } & Não possui & 231 & $80 \%$ & 215 & $82 \%$ \\
& Posse & 15 & $5 \%$ & 17 & $6 \%$ \\
& compartilhada & 43 & $15 \%$ & 30 & $11 \%$ \\
\hline \multirow{2}{*}{ Smartphone } & Posse exclusiva & 75 & $26 \%$ & 104 & $36 \%$ \\
& Sim & 214 & $74 \%$ & 183 & $64 \%$ \\
\hline
\end{tabular}

Tabela 1 - Tipo de posse dos dispositivos móveis.

Fonte: Resultados da pesquisa (2013)

Quanto à média da frequência com que os estudantes que possuem notebook levam o dispositivo à instituição durante a semana, relacionando-a ao tipo de posse do dispositivo (se compartilhada ou exclusiva). Percebe-se que, na instituição pública, aqueles que detêm a posse exclusiva levariam mais vezes o dispositivo (1,68 vezes). Já na instituição privada (1,25 vezes). Destaca-se, que os estudantes da instituição privada estão menos propensos a trazer o próprio equipamento, ver tabela 2 .

Esses elementos comportamentais devem ser analisados a luz da perspectiva do nível de integração das práticas educacionais e a utilização destes dispositivos, o que leva a acreditar que este baixo nível de propensão representa um nível não significativo de integração, o que leva a questão da socialização da tecnologia digital e a sua relação com as ferramentas pedagógicas que devem ser simultaneamente abordadas duran a definição de estratégias de BYOD, de acordo com Margaryan, Littlejohn e Vojt (2011). 


\begin{tabular}{l|ll} 
& $\begin{array}{l}\text { Instit. } \\
\text { Pública }\end{array}$ & Instit. Privada \\
\cline { 2 - 3 } & Notebook & Notebook \\
\hline Posse compartilhada & 0,56 & 0,98 \\
Posse exclusiva & 1,68 & 1,25 \\
\hline Todos os estudantes* & 1,51 & 1,19 \\
\hline
\end{tabular}

Nota: * Todos os estudantes que possuíam o dispositivo

Tabela 2- Propensão de levar o notebook à instituição

Fonte: Resultados da pesquisa (2013)

Os discentes também foram questionados a respeito das razões mais importantes para levar o notebook ou tablet à instituição. Os resultados estão dispostos na tabela 3. De acordo com os respondentes da instituição pública, o principal motivo para trazer o notebook é "a melhor funcionalidade em comparação aos computadores da universidade" (25\%). Neste caso, os alunos evitam o uso dos computadores da instituição porque estes não oferecem o desempenho esperado pelos discentes, sobretudo, em termos de aplicações e velocidade.

A segunda razão para se levar o notebook para a instituição foi o "conforto em usar" (21\%). Outro motivo é evitar os "laboratórios de computadores lotados" (20\%). Em comparação com a instituição privada, os resultados são semelhantes, destacando que para os alunos da instituição privada o principal motivo para levar o dispositivo foi o "conforto em usar" (24\%), seguido pela "a melhor funcionalidade em comparação aos computadores da universidade" (21\%) e, por fim, os “computadores da universidade, muitas vezes estão ocupados" (20\%).

A tabela 3 também apresenta os dados concernentes aos motivos mais importantes para levar o tablet para a instituição pública e instituição privada. Para os alunos de ambas instituições, a razão mais relevante para levar o tablet refere-se a sua maleabilidade para uso em pequenos períodos. Em determinadas situações, os discentes realizam pesquisas na internet, bem como acessam o ambiente virtual de aprendizagem da instituição, justificando o uso do dispositivo em períodos pequenos, porém frequentes. O segundo motivo mais apontado pelos alunos da instituição pública e instituição privada trata de "outras razões para o uso na universidade". Os estudantes acessam informações essenciais em diversos locais e ocasiões, tais como, no trânsito para universidade ou no refeitório. A terceira razão elencada pelos alunos da instituição pública difere do que foi afirmado pelos alunos da instituição privada. Para os alunos da instituição pública esta razão trata do conforto em usar o dispositivo (16\%).

Neste caso, os alunos percebem que o tablet proporciona integração entre as equipes de trabalho, pois, é fácil de transportar e usar. Já a terceira razão elencada pelos alunos da instituição privada, com 15\%, é a "melhor funcionalidade do que os computadores da universidade" que reflete melhor os anseios dos alunos.

Neste sentido temos na tablea 3 a representação de pontos importantes desta temática que corroboram os resultados alcançados por Ozcelik e Acarturk (2011) onde a funcionalidade dos 
dispositivos móveis é apontada como um motivador para a adoção desta TI, o que potencializaria a aprendizagem dos alunos.

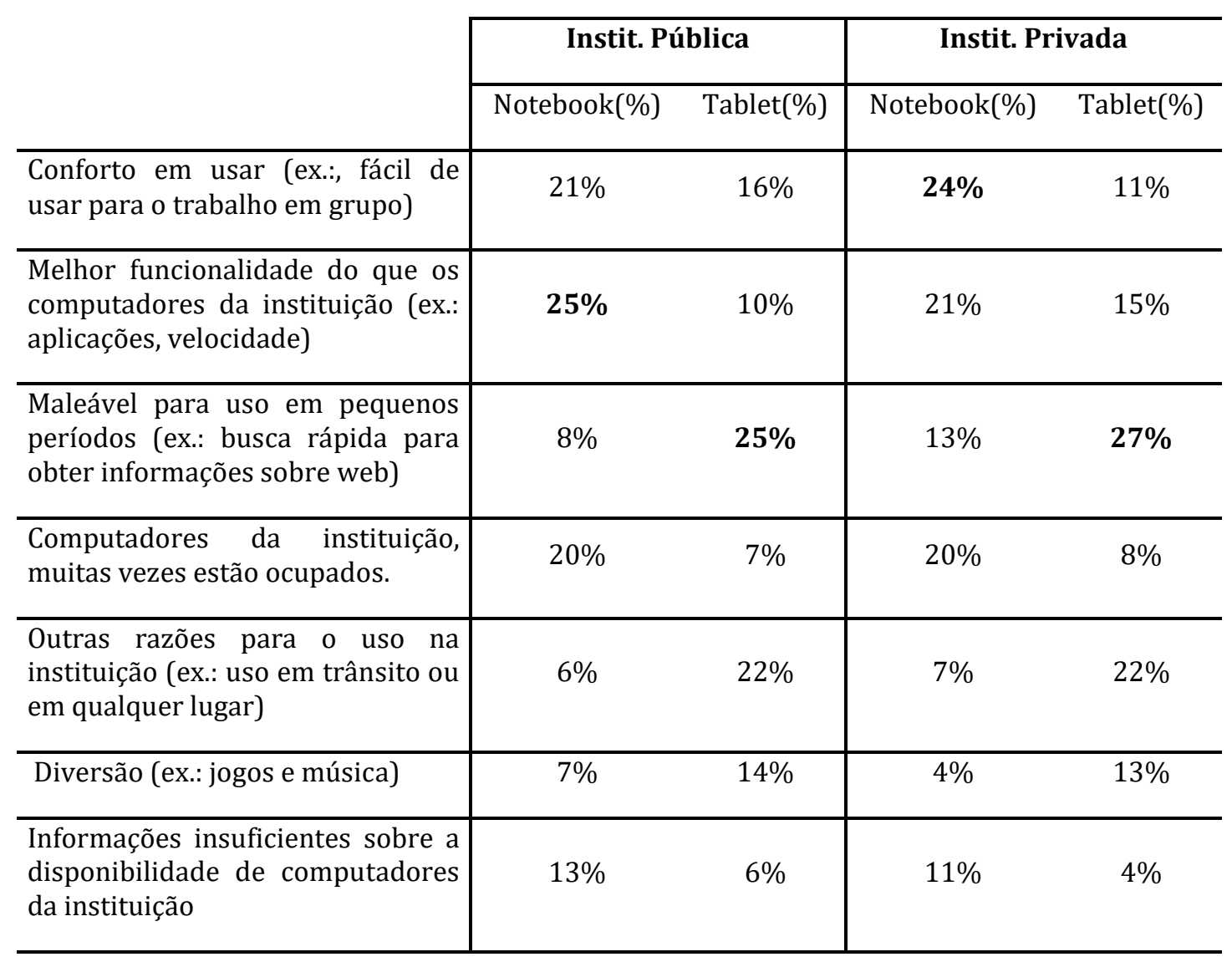

Tabela 3 - Motivos mais importantes para levar o dispositivo à instituição.

Fonte: Resultados da pesquisa (2013)

Também foram apresentados aos discentes fatores que representariam razões para que os mesmos não trouxessem o dispositivo à instituição pública. Assim, conforme a tabela 4 "o medo de que o notebook seja roubado" é o fator mais representativo das razões para não trazer o notebook à instituição, seguido pela insuficiência de instalações e o incômodo causado pelo peso do equipamento durante o seu transporte, o que também foi constatado por Kobus, Rietveld e Ommeren (2013). Isto foi elencado pelos alunos de ambas as instituições. Os alunos das duas instituições destacaram também a WIFI do campus a falta de um ambiente adequado para a utilização e o medo de danificar o dispositivo.

Portanto, os alunos de ambas as instituições de ensino convergiram para as mesmas respostas, indicando, sobretudo, a sensação de insegurança ao transitar ou usar o equipamento nas instituições, o que representa a necessidade de que as IES devem promover a criação de um ambiente que favoreça o ensino e o processo de aprendizagem, fornecendo a infraestrutura necessária aos discentes e docentes para usufruírem das possibilidades educacionais desta TI, de acordo com Idrus e Ismail (2010). 


\begin{tabular}{l|cc} 
& $\begin{array}{c}\text { Instit. } \\
\text { Pública }\end{array}$ & $\begin{array}{c}\text { Instit. } \\
\text { Privada }\end{array}$ \\
\cline { 2 - 3 } & $(\%)$ & $(\%)$ \\
\hline O notebook é pesado para ser transportado & $20 \%$ & $16 \%$ \\
Medo de que o notebook seja roubado & $\mathbf{2 3 \%}$ & $\mathbf{2 9 \%}$ \\
Falta de acesso a impressoras na instituição & $4 \%$ & $5 \%$ \\
Falta de um ambiente de trabalho mais confortável para usar / ergonômico & $7 \%$ & $8 \%$ \\
Medo de danificar o notebook & $7 \%$ & $7 \%$ \\
Falta de acesso a WiFi do campus & $11 \%$ & $13 \%$ \\
Instalações insuficientes para uso do notebook na instituição (ex.:, tomadas, \\
mesas especialmente equipadas) & $21 \%$ & $18 \%$ \\
Software necessário não está instalado no notebook & $1 \%$ & $1 \%$ \\
Especificações técnicas (ex.: hardware incompatível) & $1 \%$ & $1 \%$ \\
Não se lembrar de levar o notebook para a instituição & $4 \%$ & $3 \%$ \\
Não querer trazer, pois, não há necessidade & $0 \%$ & $0 \%$ \\
\hline
\end{tabular}

Tabela 4 - Razões mais importantes para não levar o notebook à instituição.

Fonte: Resultados da pesquisa (2013)

Tendo em vista compreender os efeitos da adoção de uma estratégia de BYOD em diferentes grupos de estudantes do curso de Administração, foi questionada aos discentes a opinião dos mesmos quanto ao uso obrigatório do notebook na IES a qual pertence. Para isso, os estudantes foram inqueridos quanto a sua percepção das consequências da obrigatoriedade do uso do próprio notebook, através de uma escala de Likert de cinco pontos. A referida escala apresenta três dimensões, a saber: má ideia (grandes, regulares e pequenas consequências), neutro e boa ideia. Por conveniência, a primeira dimensão encontra-se dividida em três categorias, permitindo o discente indicar o tamanho da consequência, quando este perceber que o uso obrigatório do notebook for uma "má ideia".

Os resultados pertencentes à questão sobre o uso obrigatório do notebook podem ser observados na tabela 5. Verifica-se, inicialmente, que $28 \%$ dos respondentes da instituição pública possuem uma percepção negativa quanto à estratégia de adoção obrigatória do notebook. Isto é, os discentes acreditam que é uma "má ideia" empregar essa abordagem, sendo que $9 \%$ afirmam que o uso obrigatório do dispositivo resultará em grandes consequências. Vale ressaltar, que essas consequências estão relacionadas a elementos desfavoráveis ao emprego obrigatório do equipamento.

A coluna 4 mostra que $40 \%$ dos estudantes compartilham uma postura "neutra" quanto ao uso obrigatório do dispositivo, enquanto que 32\% acreditam que essa abordagem é uma "boa ideia". A postura "neutra" dos alunos representa o maior percentual entre as dimensões da escala. Essa 
neutralidade expõe a indiferença dos respondentes sobre a obrigatoriedade do uso do notebook. Já o segundo maior percentual (boa ideia), que corresponde a $32 \%$, pode ser explicado pela quantidade de alunos com a posse exclusiva de notebook, totalizando $69 \%$, e que não vislumbram desvantagens significativas em trazer o dispositivo para instituição. Ademais, constata-se na tabela 5, que os diferentes grupos de estudantes inqueridos reproduzem comportamentos semelhantes ao considerar o uso do notebook obrigatório.

Tabela 5 - Opiniões sobre fazer o uso obrigatório do próprio notebook nas atividades do curso.

\begin{tabular}{|c|c|c|c|c|c|c|c|}
\hline & & $\begin{array}{c}\text { № de } \\
\text { observações }\end{array}$ & $\begin{array}{c}\text { Má ideia, } \\
\text { grandes } \\
\text { consequência } \\
\text { s (\%) }\end{array}$ & $\begin{array}{c}\text { Má ideia, } \\
\text { consequênci } \\
\text { as regulares } \\
(\%)\end{array}$ & $\begin{array}{c}\text { Má ideia, } \\
\text { consequência } \\
\text { s pequenas } \\
(\%)\end{array}$ & $\begin{array}{c}\text { Neutr } \\
\text { o } \\
(\%)\end{array}$ & $\begin{array}{c}\text { Boa } \\
\text { idei } \\
\text { a } \\
(\%)\end{array}$ \\
\hline \multirow{2}{*}{$\begin{array}{l}\text { Todos os } \\
\text { estudantes }\end{array}$} & $\begin{array}{l}\text { Instit. } \\
\text { Pública }\end{array}$ & 288 & $9 \%$ & $10 \%$ & $9 \%$ & $40 \%$ & $32 \%$ \\
\hline & $\begin{array}{l}\text { Instit. } \\
\text { Privada }\end{array}$ & 288 & $13 \%$ & $16 \%$ & $5 \%$ & $32 \%$ & $35 \%$ \\
\hline \multirow[b]{2}{*}{ Feminino } & $\begin{array}{l}\text { Instit. } \\
\text { Pública }\end{array}$ & 124 & $9 \%$ & $8 \%$ & $10 \%$ & $45 \%$ & $28 \%$ \\
\hline & $\begin{array}{l}\text { Instit. } \\
\text { Privada }\end{array}$ & 157 & $11 \%$ & $17 \%$ & $5 \%$ & $36 \%$ & $31 \%$ \\
\hline \multirow{2}{*}{ Noturno } & $\begin{array}{l}\text { Instit. } \\
\text { Pública }\end{array}$ & 134 & $14 \%$ & $7 \%$ & $10 \%$ & $32 \%$ & $37 \%$ \\
\hline & $\begin{array}{l}\text { Instit. } \\
\text { Privada }\end{array}$ & 212 & $13 \%$ & $16 \%$ & $5 \%$ & $30 \%$ & $36 \%$ \\
\hline \multirow{2}{*}{$\begin{array}{l}\text { Renda do aluno } \\
<\mathrm{R} \$ 678,00\end{array}$} & $\begin{array}{l}\text { Instit. } \\
\text { Pública }\end{array}$ & 127 & $9 \%$ & $9 \%$ & $6 \%$ & $47 \%$ & $29 \%$ \\
\hline & $\begin{array}{l}\text { Instit. } \\
\text { Privada }\end{array}$ & 95 & $16 \%$ & $9 \%$ & $7 \%$ & $28 \%$ & $39 \%$ \\
\hline \multirow{2}{*}{$1^{\circ}$ ano de estudo } & $\begin{array}{l}\text { Instit. } \\
\text { Pública }\end{array}$ & 78 & $6 \%$ & $10 \%$ & $6 \%$ & $50 \%$ & $27 \%$ \\
\hline & $\begin{array}{l}\text { Instit. } \\
\text { Privada }\end{array}$ & 69 & $10 \%$ & $12 \%$ & $3 \%$ & $36 \%$ & $39 \%$ \\
\hline
\end{tabular}

Tabela 5 - Opiniões sobre fazer o uso obrigatório do próprio notebook nas atividades do curso.

Fonte: Resultados da pesquisa (2013)

As respostas apresentadas pelos alunos da instituição privada são semelhantes. Observa-se que $34 \%$ dos respondentes da instituição privada possuem uma percepção negativa quanto à estratégia de adoção obrigatória do notebook. Destes, $16 \%$ afirmam que o uso obrigatório do dispositivo resultará em consequências regulares, e 13\% em grandes consequências. A coluna 4 indica que $32 \%$ dos estudantes compartilham uma postura "neutra" quanto ao uso obrigatório do dispositivo, enquanto que 35\% acreditam que essa abordagem é uma "boa ideia". Pode-se inferir que a estratégia de adoção do uso obrigatório do próprio notebook nas atividades do curso, considerando as duas instituições, não é um consenso entre os respondentes. $\mathrm{Na}$ instituição pública, $68 \%$ dos alunos entendem que essa estratégia é uma má ideia ou possuem 


\section{Carlos David Cequeira Feitor, Marcos Paulo da Silva, Manoel Veras de Sousa Neto, Adrianne Paula Vieira de Andrade}

uma postura neutra, e na instituição privada 66\% corroboram com a atitude dos alunos da instituição pública.

As percepções neutras ou favoráveis ao uso obrigatório dos dispositivos eletrônicos móveis, representam uma propensão a adoção desta TI no ambiente de ensino superior, no entanto, deve-se ressaltar que a estratégia do uso obrigatório do próprio dispositivo requer esclarecimentos, visando dirimir as dúvidas dos estudantes quanto a sua adoção, bem como oferecer a infraestrutura e segurança adequadas, ao levar em consideração a percepção negativa dos discentes, constatada por Kobus, Rietveld e Ommeren (2013).

\section{Análise Não Paramétrica}

0 teste de Mann-Whitney apresentado na tabela 6, a qual mostra a comparação entre as principais razões para não trazer o notebook à instituição com o tipo de instituição onde os indivíduos estudam.

Esta análise foi realizada levando em consideração dois subgrupos que são os indivíduos que estudam em uma instituição pública e em uma instituição privada. Inicialmente, foram identificadas diferenças estatísticas em relação à instituição em que estudam e as razões para não levar o notebook à instituição. Conforme pode ser visto na tabela 7 , três assertivas se mostraram significantes.

\begin{tabular}{l|c|c|c|c}
\hline \multicolumn{1}{c|}{$\begin{array}{c}\text { Principais razões para não trazer o } \\
\text { notebook à instituição }\end{array}$} & $\begin{array}{c}\text { U de Mann } \\
\text { Whitney }\end{array}$ & Desvio (Z) & Significância & Hipótese \\
\hline $\begin{array}{l}\text { O notebook é pesado para ser } \\
\text { transportado }\end{array}$ & 34083,000 & $-4,453$ &, $\mathbf{0 0 0}$ & $\mathbf{S}^{*}$ \\
\hline Medo de que o notebook seja roubado & 38569,500 & $-2,273$ &, $\mathbf{0 2 3}$ & $\mathbf{S}^{*}$ \\
\hline $\begin{array}{l}\text { Falta de acesso a impressoras na } \\
\text { instituição }\end{array}$ & 40481,500 & $-1,070$ &, 284 & NS \\
\hline $\begin{array}{l}\text { Falta de um ambiente de trabalho mais } \\
\text { confortável para usar / ergonômico }\end{array}$ & 41716,500 &,- 030 &, 976 & NS \\
\hline $\begin{array}{l}\text { Medo de danificar o notebook } \\
\text { Falta de acesso a WiFi do campus }\end{array}$ & 41229,000 &,- 367 &, 714 & NS \\
\hline $\begin{array}{l}\text { Instalações insuficientes para uso do } \\
\text { notebook na instituição (ex.:, tomadas, } \\
\text { mesas especialmente equipadas }\end{array}$ & 34588,000 & $-4,233$ &, $\mathbf{0 0 0}$ & NS \\
\hline $\begin{array}{l}\text { Software necessário não está instalado no } \\
\text { notebook }\end{array}$ & 40884,000 & $-1,450$ &, 147 & NS \\
\hline $\begin{array}{l}\text { Especificações técnicas (ex.: hardware } \\
\text { incompatível }\end{array}$ & 40884,000 & $-1,450$ &, 147 & NS \\
\hline $\begin{array}{l}\text { Não lembrar de trazer o notebook para a } \\
\text { instituição }\end{array}$ & 40572,000 & $-1,089$ &, 276 & NS \\
\hline $\begin{array}{l}\text { Não querer trazer pois acha que não há } \\
\text { necessidade }\end{array}$ & 41325,000 & $-1,741$ &, 082 & NS \\
\hline
\end{tabular}

S*- Hipótese suportada, através da prova estatística a um nível de significância de 0,05 
Tabela 6- Comparação das razões para não levar o notebook à instituição com a variável tipo de instituição de ensino superior.

Fonte: Resultados da pesquisa (2013)

Os alunos da instituição pública (posto médio $=316,16$ ) concordam mais que os da privada (posto médio $=263,03$ ) que o notebook é pesado para ser transportado e isso pode fazer com que eles não levem o equipamento à instituição. Outra questão que também foi significante foi o medo de que o notebook seja roubado que pareceu ser mais evidente para os alunos da instituição privada (posto médio $=300,50$ ) que os da pública (posto médio $=278,42$ ). Os alunos da instituição pública (posto médio $=314,40$ ) foram mais propensos a afirmar que as instalações insuficientes da instituição é uma das principais razões para eles não levarem o notebook à instituição. Isto pode ser visualizado na tabela 7.

\begin{tabular}{l|c|c|c}
\hline \multicolumn{1}{c|}{$\begin{array}{c}\text { Principais razões para não levar o } \\
\text { notebook à instituição }\end{array}$} & Universidade & Postos médios & $\begin{array}{c}\text { Soma dos } \\
\text { postos }\end{array}$ \\
\hline \multirow{2}{*}{ O notebook é pesado para ser transportado } & Privada & 263,03 & 76278,00 \\
\cline { 2 - 4 } & Pública & 316,16 & 91053,00 \\
\hline \multirow{2}{*}{\begin{tabular}{l} 
Medo de que o notebook seja roubado \\
\cline { 2 - 4 } insuficientes para uso do
\end{tabular}} & Privada & 300,50 & 87145,50 \\
\hline $\begin{array}{l}\text { Instalações } \\
\text { notebook na instituição (ex.: tomadas, mesas } \\
\text { especialmente equipadas Privada }\end{array}$ & 278,42 & 80185,50 \\
\cline { 2 - 4 } & Pública & 314,40 & 76783,00 \\
\hline
\end{tabular}

Tabela 7 - Postos médios de Mann-Whitney para itens com significância em relação às principais razões para não levar o notebook à instituição e o tipo de instituição de ensino superior.

Fonte: Resultados da pesquisa (2013)

Novamente, percebe-se que aspectos sociais e econômicos influenciando a adoção de estratétigas de BYOD pelos discentes, o que reitera a necessidade de disponibilização de uma infraestrutura adequada as atividades educacionais decorrentes da adoção desta TI, conforme (KOBUS; RIETVELD; OMMEREN, 2013; IDRUS; ISMAIL, 2010).

Em seguida foram avaliados os principais motivos para levar o notebook e o tablet à instituição em relação ao tipo de instituição que estudam. A tabela 8 mostra que quatro motivos foram significantes estatisticamente para o notebook. 


\section{Carlos David Cequeira Feitor, Marcos Paulo da Silva, Manoel Veras de Sousa Neto, Adrianne Paula Vieira de Andrade}

\begin{tabular}{|c|c|c|c|c|c|c|c|c|}
\hline \multirow[b]{2}{*}{$\begin{array}{l}\text { Principais motivos para } \\
\text { levar o dispositivo à } \\
\text { instituição }\end{array}$} & \multicolumn{4}{|c|}{ Notebook } & \multicolumn{4}{|c|}{ Tablet } \\
\hline & $\begin{array}{l}\text { U de } \\
\text { Mann } \\
\text { Whitn } \\
\text { ey }\end{array}$ & $\begin{array}{l}\text { Desvi } \\
\text { o (Z) }\end{array}$ & Sig. & $\begin{array}{l}\text { Hipóte } \\
\text { se }\end{array}$ & $\begin{array}{l}\text { U de } \\
\text { Mann } \\
\text { Whitn } \\
\text { ey }\end{array}$ & $\begin{array}{l}\text { Desvi } \\
\text { o (Z) }\end{array}$ & Sig. & $\begin{array}{l}\text { Hipóte } \\
\text { se }\end{array}$ \\
\hline $\begin{array}{l}\text { Conforto em usar (ex.:, } \\
\text { fácil de usar para o } \\
\text { trabalho em grupo) }\end{array}$ & 39951 & $\begin{array}{c}- \\
1,187\end{array}$ & $\begin{array}{c}0,23 \\
5\end{array}$ & NS & $\begin{array}{l}29582 \\
5\end{array}$ & $\begin{array}{c}- \\
7,095\end{array}$ & 0 & $\mathbf{S}^{*}$ \\
\hline $\begin{array}{l}\text { Melhor funcionalidade do } \\
\text { que os computadores da } \\
\text { instituição (ex.: } \\
\text { aplicações, velocidade) }\end{array}$ & 33732 & $\begin{array}{c}- \\
5,527\end{array}$ & 0 & $S^{*}$ & 39891 & $\begin{array}{c}- \\
1,117\end{array}$ & $\begin{array}{c}0,26 \\
4\end{array}$ & NS \\
\hline $\begin{array}{l}\text { Maleável para uso em } \\
\text { pequenos períodos (ex.: } \\
\text { busca rápida para obter } \\
\text { informações sobre web) }\end{array}$ & $\begin{array}{l}36553 \\
5\end{array}$ & $-3,15$ & $\begin{array}{c}0,00 \\
2\end{array}$ & $\mathbf{S}^{*}$ & 32880 & $\begin{array}{c}- \\
6,184\end{array}$ & $\mathbf{0}$ & $\mathbf{S}^{*}$ \\
\hline $\begin{array}{lr}\text { Computadores } & \text { da } \\
\text { instituição, muitas } & \text { vezes } \\
\text { estão ocupados. }\end{array}$ & 39255 & $-1,53$ & $\begin{array}{c}0,12 \\
6\end{array}$ & NS & 39239 & $\begin{array}{c}- \\
1,741\end{array}$ & $\begin{array}{c}0,08 \\
2\end{array}$ & NS \\
\hline $\begin{array}{l}\text { Outras razões para o uso } \\
\text { na instituição (ex.: uso em } \\
\text { trânsito ou em qualquer } \\
\text { lugar) }\end{array}$ & 40957 & $\begin{array}{c}- \\
0,556\end{array}$ & $\begin{array}{c}0,57 \\
8\end{array}$ & NS & 33155 & $\begin{array}{c}- \\
5,188\end{array}$ & $\mathbf{0}$ & $\mathbf{S}^{*}$ \\
\hline $\begin{array}{l}\text { Diversão (ex.: jogos } \mathrm{e} \\
\text { música) }\end{array}$ & 36502 & $\begin{array}{c}- \\
3,826\end{array}$ & $\mathbf{0}$ & $\mathbf{S}^{*}$ & 35138 & $\begin{array}{c}- \\
3,867\end{array}$ & $\mathbf{0}$ & $\mathbf{S}^{*}$ \\
\hline $\begin{array}{l}\text { Informações insuficientes } \\
\text { sobre a disponibilidade de } \\
\text { computadores da } \\
\text { instituição }\end{array}$ & $\begin{array}{l}37966 \\
5\end{array}$ & $\begin{array}{c}- \\
2,223\end{array}$ & $\begin{array}{c}0,02 \\
6\end{array}$ & $\mathbf{S}^{*}$ & 37959 & $\begin{array}{c}- \\
3,043\end{array}$ & $\begin{array}{c}0,00 \\
2\end{array}$ & $\mathbf{S}^{*}$ \\
\hline
\end{tabular}

$S^{*}$ - Hipótese suportada, através da prova estatística a um nível de significância de 0,05

Tabela 8 - Postos médios de Mann-Whitney para itens com significância em relação aos principais motivos para levar o notebook à instituição e o tipo de instituição de ensino superior.

Fonte: Resultados da pesquisa (2013)

Quanto às razões para levar o notebook à instituição, foi possível destacar algumas distinções relevantes nas opiniões dos alunos da instituição pública e privada. Os alunos da instituição pública (posto médio $=317,38$ ) concordam mais que os da privada (posto médio $=261,82$ ) que um dos principais motivos para eles levarem o seu notebook à instituição é a melhor funcionalidade dos seus equipamentos se comparados com os da Instituição. Isso parece mostrar que a insatisfação com o equipamento da instituição é um motivador para que os alunos da instituição pública utilizem seu notebook no ambiente acadêmico. Em contrapartida, o fato do notebook ser maleável para busca de informações em pequenos períodos foi mais evidente para os alunos da instituição privada (posto médio $=307,45$ ) que os da pública (posto médio $=271,42$ ). Além disso, os alunos da instituição pública tenderam a concordar mais que os da privada que levam o notebook para a instituição devido ao uso dele para a diversão e 
também devido à falta de informações suficientes sobre os computadores disponíveis na Instituição. Estes resultados podem ser visualizados na tabela 9.

\begin{tabular}{l|c|c|c}
\hline \multicolumn{1}{c|}{$\begin{array}{c}\text { Principais motivos para levar } \\
\text { notebook à instituição }\end{array}$} & Universidade & $\begin{array}{c}\text { Postos } \\
\text { médios }\end{array}$ & Soma dos postos \\
\hline $\begin{array}{l}\text { Melhor funcionalidade do que os } \\
\text { computadores da instituição (ex.: } \\
\text { aplicações, velocidade) }\end{array}$ & Privada & 261,82 & 75927,00 \\
\cline { 2 - 4 } & Pública & 317,38 & 91404,00 \\
\hline $\begin{array}{l}\text { Maleável para uso em pequenos } \\
\text { períodos (ex.: busca rápida para obter } \\
\text { informações sobre web) }\end{array}$ & Privada & 307,45 & 89161,50 \\
\cline { 2 - 4 } $\begin{array}{l}\text { Diversão (ex.: jogos e música) } \\
\text { Pública }\end{array}$ & Privada & 271,42 & 78169,50 \\
\cline { 2 - 4 } & Pública & 307,76 & 78697,00 \\
\hline $\begin{array}{l}\text { Informações insuficientes sobre a } \\
\text { disponibilidade de computadores da } \\
\text { instituição }\end{array}$ & Privada & 276,42 & 88634,00 \\
\cline { 2 - 4 } & Pública & 302,67 & 80161,50 \\
\hline
\end{tabular}

Tabela 9 - Postos médios de Mann-Whitney para itens com significância em relação aos principais motivos para levar o notebook à instituição e o tipo de instituição de ensino superior.

Fonte: Resultados da pesquisa (2013)

Além do uso do notebook na instituição de ensino, também foi analisado o uso do tablet de acordo com a instituição em que os respondentes estudam. Os resultados mostraram que os estudantes da instituição pública mostraram-se mais propensos a concordar com cinco motivos para o uso do tablet na instituição. Aliado a isso, as estatísticas descritivas mostraram que a posse exclusiva do tablet por parte dos alunos da instituição pública é maior que a dos alunos da instituição privada. Deste modo, um motivo que foi estatisticamente significante foi o conforto em usar o tablet para a realização de trabalhos em grupo. Os alunos da instituição pública (posto médio $=331,78$ ) destacaram mais esta motivação que os da privada (posto médio $=247,51$ ). Os estudantes da instituição pública também demonstraram ser mais propensos (posto médio = 320,33 ) a afirmar que o tablet é maleável para uso em pequenos períodos e isso os motiva a levá-lo para a instituição.

A tabela 10 mostra que os estudantes da instituição pública também concordaram mais (posto médio $=319,38$ ) que levam o tablet à instituição devido a outras razões para uso na instituição. Além disso, o uso do tablet para a diversão também apresentou um posto médio maior para os alunos da instituição pública (posto médio $=312,49$ ) que para os alunos da instituição privada (posto médio = 266,67).

\begin{tabular}{l|c|c|c}
\hline \multicolumn{1}{c|}{$\begin{array}{c}\text { Principais motivos para levar o tablet à } \\
\text { instituição }\end{array}$} & Universidade & $\begin{array}{c}\text { Postos } \\
\text { médios }\end{array}$ & Soma dos postos \\
\hline $\begin{array}{l}\text { Conforto em usar (ex.:, fácil de usar para o } \\
\text { trabalho em grupo) }\end{array}$ & Privada & 247,51 & 71777,50 \\
\cline { 2 - 4 } & Pública & 331,78 & 95553,50 \\
\hline $\begin{array}{l}\text { Maleável para uso em pequenos períodos } \\
\text { (ex.: busca rápida para obter informações } \\
\text { sobre web) }\end{array}$ & Privada & 258,88 & 75075,00 \\
\cline { 2 - 4 } & Pública & 320,33 & 92256,00 \\
\hline
\end{tabular}




\section{Carlos David Cequeira Feitor, Marcos Paulo da Silva, Manoel Veras de Sousa Neto, Adrianne Paula Vieira de Andrade}

\begin{tabular}{l|c|c|c}
\hline \multirow{2}{*}{$\begin{array}{l}\text { Outras razões para o uso na instituição (ex.: } \\
\text { uso em trânsito ou em qualquer lugar) }\end{array}$} & Privada & 259,83 & 75350,00 \\
\cline { 2 - 4 } & Pública & 319,38 & 91981,00 \\
\hline \multirow{2}{*}{ Diversão (ex.: jogos e música) } & Privada & 266,67 & 77333,00 \\
\cline { 2 - 4 } & Pública & 312,49 & 89998,00 \\
\hline $\begin{array}{l}\text { Informações insuficientes sobre a } \\
\text { disponibilidade de computadores da } \\
\text { instituição }\end{array}$ & Privada & 276,39 & 80154,00 \\
\cline { 2 - 4 } & Pública & 302,70 & 87177,00 \\
\hline
\end{tabular}

Tabela 10 - Postos médios de Mann-Whitney para itens com significância em relação aos principais motivos para levar o tablet à instituição e o tipo de instituição de ensino superior.

Fonte: Resultados da pesquisa (2013)

Por fim, os alunos da instituição pública também concordaram mais que as informações insuficientes sobre a disponibilidade de computadores fornecida pela IES seja um dos motivos para eles levarem o tablet à instituição, o que corrobora com a análise anterior com relação a este motivo e o uso do notebook na instituição por parte dos estudantes da instituição pública.

Deste modo, apesar da socialização da posse dos disposutivos móveis, pode-se perceber que a implementação de políticas pedagógicas se faz necessária a fim de direcionar a funcionalidade percebida pelos discentes às atividades de ensino promovidas pelo curso e com isso aumentar a propensão dos discentes trazerem os seus dispositivos à instituição, em atenção às constatações feitas por (SHIN; SHIN; CHOO et al., 2011; SUNG; MAYER, 2013; MARGARYAN; LITTLEJOHN; VOJT, 2011; IDRUS; ISMAIL, 2010).

\section{Considerações Finais}

O estudo abordou a adoção de dispositivos móveis por parte de estudantes de Administração de uma instituição pública e de uma instituição privada com o objetivo de identificar a propensão dos estudantes em utilizarem os seus equipamentos no ambiente acadêmico, bem como o parecer deles sobre a participação de um programa de BYOD que poderia ser viabilizado pelas instituições de ensino. A revisão de literatura mostrou alguns estudos que analisaram a adoção de dispositivos móveis e alguns aspectos que podem influenciar adoção e o uso dos dispositivos nas instituições de ensino.

A maior parte dos estudantes da instituição privada e da pública abordados no estudo possuem notebook e smartphone. A adoção de tablet ainda é baixa por parte dos alunos, apenas 15\% dos alunos da instituição pública e $11 \%$ da instituição privada detém a posse exclusiva deste dispositivo. Foi constatada uma baixa propensão dos estudantes em levarem seus dispositivos para a instituição.

Os alunos da instituição privada se mostraram menos propensos a levarem seus dispositivos à instituição se comparados com os alunos da instituição pública. Os principais motivos elencados é o medo de que o notebook seja roubado, o peso do equipamento e a insuficiência de instalações. Consequentemente, grande parte dos estudantes demonstra uma postura neutra quanto à participação em um programa de BYOD e ao uso obrigatório do notebook no ambiente acadêmico. 
Foram identificadas algumas diferenças de opiniões relacionadas à instituição em que estudam com relação às razões para eles não levarem o notebook à instituição e os motivos que os fazem levar os seus dispositivos à instituição. No entanto, apesar da existência de diferenças entre os dois grupos conclui-se que existe uma percepção favorável ou no mínimo neutra em relação a adoção de estratégias de BYOD pelas instituições.

Cabe as IES a promoção de ações pedagógicas que possam auxiliar na conscientização e adoção destas práticas de TI, em paralelo a disponibilização de uma infraestrutura adequada aos alunos o que os motivaria a trazerem os seus dispositivos a IES, aproveitando a atual ampliação do acesso aos dispositivos eletrônicos móveis.

Esta pesquisa contribui para ampliar o entendimento sobre o uso de dispositivos móveis de TI na educação e evidencia alguns aspectos socioeconômicos que influenciam na adoção de dispositivos de TI que podem afetar a participação dos estudantes em um programa de BYOD. Além disso, as razões que impulsionam os estudantes a não levarem os seus equipamentos à instituição podem ajudar os gestores das IES na elaboração de estratégias de BYOD exitosas.

\section{Referências}

ATKINSON, J.S.; SPENNEMAN, D.H.R. CORNFORTH, D. Redirecting under-utilised computer laboratories into cluster computing facilities. Campus-Wide Information Systems, v. 22, n. 4, p. 201-209, 2005.

DANCEY, C. P; REIDY, J. Estatística sem matemática para psicologia: usando SPSS para Windows. Porto Alegre: Artmed,2006.

DAVIS, M. A. BYOD. Information Week, 2012. Disponível em: <http://go.galegroup.com/ps/i.do?id=GALE|A310761212\&v=2.1\&u=capes58\&it=r\&p=AONE\&s $\mathrm{w}=\mathrm{w}>$. Acesso em: 12 maio 2013.

DEDE, Chris. Planning for neomillennial learning styles: implications for investments in technology and faculty. In: OBLINGER, Diana G.; OBLINGER, James L. Educating the net generation. Harvard University, 2005.

FINNERAN, Michael. Survive The BYOD Revolution. Information Week, n. 1314, p. 44, 2011.

FONG, M. W. L. Digital divide between urban and rural regions in china. The Electronic Journal of Information Systems in Developing Countries, v. 36, p. 1-12, 2009.

FORTSON, Kim. Creating device-neutral assignments for BYOD classes. Academic One File, 2013.

Disponível em:<http://go.galegroup.com/ps/i.do?id=GALE\%7CA324397562\&v=2.1\&u=capes58\&it=r\&p=A ONE\&sw=w>. Acesso em: 10 jun. 2013.

FRIED, Carrie B. In-class laptop use and its effects on student learning. Computers \& Education, v. 50, p. 906-914, 2008.

FURIÓ, D., GANCEDO, S., JUAN, M., SEGUÍ, I., COSTA, M. The effects of the size and weight of a mobile device on an educational game. Computers \& Education, v. 64, p. 24-41, 2013.

IDRUS, R., ISMAIL, I. Role of institutions of higher learning towards a knowledge-based community utilizing mobile devices. Procedia Social and Behavioral Sciences, v. 2, p. 2766- 


\section{Carlos David Cequeira Feitor, Marcos Paulo da Silva, Manoel Veras de Sousa Neto, Adrianne Paula Vieira de Andrade}

$2770,2010$.

JOHNSON, Doug. On board with BYOD. Educational Leadership, v. 70, n. 2, p. 84-85, 2012.

JONES, C. et al. Net generation or digital natives: is there a distinct new generation entering university? Computers \& Education, v. 54, n. 3, p. 722-732, 2010.

JUNCO, Reynol. In-class multitasking and academic performance. Computers in Human Behavior, v. 28, p. 2236-2243, 2012.

KEMSHALL, Andy. Are You Ready For BYOD 2.0?. Database and Network Journal, v. 42, n. 6, p. $12,2012$.

KIM, Y. M. Gender role and the use of university library website resources: A social cognitive theory perspective. Journal of Information Science, v.36, n.5, P.603-617,2010.

KOBUS, Martijn B.W.; RIETVELD, Piet; OMMEREN, Jos N. van. Owneship versus on-campus use of mobile IT devices by university students. Computers \& Education, v. 68, p. 29-41, 2013.

LACINA, R. Technology in the classroom: learning English with iPods. Childhood Education, 84(1), 247-249, 2008.

LÓPEZ, A., FÓRTIZ, M. J., ALMENDROS, M. L., SEGURA, M. J. Mobile learning technology based on iOS devices to support students with special education needs. Computers \& Education, v. 61, p. 77-90, 2013.

MARGARYAN, A.; LITTLEJOHN, A.; VOJT, G. Are digital natives a myth or reality? University students' use of digital technologies. Computers \& Education, v. 56, n. 2, p. 429-440, 2011.

MARINAGI, C., SKOURLAS, C., BELSIS, P. Employing ubiquitous computing devices and technologies in the higher education classroom of the future. Procedia Social and Behavioral Sciences. v. 73, p. 487-494, 2013.

MARTIN, F., ERTZBERGER, J. Here and now mobile learning: An experimental study on the use of mobile technology. Computers \& Education, v. 68, p. 76-85, 2013.

MCCONNEL, C. R.; BRUE, S. L. Microeconomia: princípios, problemas e políticas. 14. Ed. Rio de Janeiro: LTC, 2001.

MESSMER, Ellen. Are federal agency workers going rogue with personal devices? Telework Exchange survey shows BYOD policy gaps for mobile devices. Network World, 2013.

MEURANT, R. C. iPad tablet Computing to Foster Korean EFL Digital Literacy. International Journal of u- and e-Service, Science and Technology, 3(4), 49-62, 2010.

MINTZ, J.; BRANCH, C.; MARCH, C.; LERMAN, S. Key factors mediating the use of a mobile technology tool designed to develop social and life skills in children with Autistic Spectrum Disorders. Computers \& Education, v. 58, p. 53-62, 2012.

MOLINA, A., REDONDO, M., LACAVE, C., ORTEGA, M. Assessing the effectiveness of new devices for accessing learning materials: An empirical analysis based on eye tracking and learner subjective perception. Computers in Human Behavior, p. 01-16, 2013.

MORROW, B. BYOD security challenges: control and protect your most sensitive data. Network 
Security, 2012.

ONG, C-S; LAI, J-Y. Gender differences in perceptions and relationships among dominants of elearning acceptance. Computers in human behavior, v.22, p. 816- 829, 2006.

OZCELIK, E., ACARTURK, C. Reducing the spatial distance between printed and online information sources by means of mobile technology enhances learning: Using 2D barcodes. Computers \& Education, v. 57, p. 2077-2085, 2011.

PADMANABHAN, P., WISE, A. F. Exploring situational factors shaping access in a laptop program for socially disadvantaged children in India: a case study. Educational Media International, $v$. 49, n. 2, p. 81-95, 2010.

PETTEY, C., MEULEN, R. V. Gartner's 2012 hype cycle for emerging technologies identifies "Tipping Point" technologies that will unlock long-awaited technology scenarios. Newsroom, 2012.

ROCKINSON- SZAPKIW, A., COURDUFF, J., CARTER, K., BENNETT, D. Electronic versus traditional print textbooks: A comparison study on the influence of university students' learning. Computers \& Education. v. 63, p. 259-266, 2013.

SAUTTER, J. M., TIPPETT, R. M., MORGAN, S. P. The social demography of internet dating in the United States. Social Science Quarterly, v. 91, n. 2, p. 554-575, 2010.

SHEPPARD, D. Reading with iPads - the difference makes a difference. Education Today, 3, 12$15,2011$.

SHIN, Dong-Hee, SHIN, Youn-Joo, CHOO, H., BEOM, K. Smartphones as smart pedagogical tools: Implications for smartphones as u-learning devices. Computers in Human Behavior, v. 27, p. 2207-2214, 2011.

STIGLITZ, J. E.; WALSH, C. E. Introdução à microeconomia. 3. ed. 7. reimpr. Rio de Janeiro: Campus, 2003.

SUNG, Eunmo., MAYER, Richard. Online multimedia learning with mobile devices and desktop computers: An experimental test of Clark's methods-not-media hypothesis. Computers in Human Behavior, v. 29, p. 639-647, 2013.

TALEB, Z., SOHRABI, A. Learning on the move: the use of mobile technology to support learning for university students. Procedia Social and Behavioral Sciences. v. 69, p. 1102-1109, 2012.

TALUKDAR, D., GAURI, D. K. Home internet access and usage in the USA: trends in the socioeconomic digital divide. Communications of the Association for information Systems. v. 28, n. 7, p. 84-99, 2011.

Tamim, R. M; Lowerison, G; Schmid, R. F; Bernard, R. M; Abrami, P. C. (2011). A multiyear investigation of the relationship between pedagogy, computer use and course effectiveness in postsecondary education. Journal of Computing in Higher Education, v. 23, p. 1-14, 2011.

THOMSON, G. BYOD: enabling the chaos. Network Security. 2012. Disponível em: <http://www.sciencedirect.com/science/article/pii/S1353485812700132>. Acesso em: 10 abr. 2013. 


\section{Carlos David Cequeira Feitor, Marcos Paulo da Silva, Manoel Veras de Sousa Neto,}

Adrianne Paula Vieira de Andrade

TOKUYOSHI, Brian. The security implications of BYOD. Network Security, v. 2013, n. 4, p. 1213, 2013.

VARIAN, H. R. Microeconomia. Princípios Básicos, Uma Abordagem Moderna. Tradução da 7a Edição. Editora Campus, 2006.

VASCONCElloS, M. A. S.; OLIVEIRA, R. G. Manual de microeconomia. 2. ed. 6. reimpr. São Paulo: Atlas, 2009.

VEKIRI, I. Socioeconomic differences in elementary students ICT beliefs and out-school experiences. Computers \& Education, v. 54, n. 4, p. 941-950, 2010.

VICKERMON, Jodie A. Bring your own device to work. Risk Management, 2013. 